\title{
O AUTORITARISMO E A VIOLÊNCIA EM O REI BRANCO, DE GYÖRGY DRAGOMÁN
}

\author{
Jildonei Lazzaretti ${ }^{1}$ \\ Adriana Claudia Martins ${ }^{2}$
}

Resumo: Este artigo consiste em uma análise da obra O rei branco, de György Dragomán, a partir dos conceitos de autoritarismo e de violência, a fim de constatar como a narrativa se desenvolve em relação a essas duas temáticas. Nesse sentido, são consideradas as definições de "autoritarismo" e "violência" presentes no Dicionário de Política, de Bobbio el al. (1998), bem como a reflexão teórica e alegórica de Wolfgang Sofsky no Tratado sobre la violencia (2006). Além disso, são também analisadas as referências históricas utilizadas na construção ficcional da narrativa, a fim de compreender as especificidades do regime autoritário e violento mencionado na obra. Desta forma, a presente análise demonstra a centralidade dos conceitos de autoritarismo e de violência em $O$ rei branco, sendo determinantes, não apenas para o desenvolvimento do enredo, como também para a transformação do narrador-personagem: Dzsátá.

Palavras-chave: Autoritarismo; Violência; György Dragomán; $O$ rei branco.

\begin{abstract}
This article consists of an analysis of The White King novel, which is written by György Dragomán. The study considers the concepts of authoritarianism and violence in order to verify how the narrative develops in relation to these two themes. In this way, the definitions of "authoritarianism" and "violence" are considered from Bobbio's Dictionary of Politics (1998), as the theoretical and allegorical reflection are from Wolfgang Sofsky, in his publication Tratado sobre la violencia (2006). In addition, the historical references used in the fictional construction of the narrative are also examined in order to be understood the specificities of the authoritarian and violent regime mentioned in the novel. Thus, the present analysis demonstrates the centrality of the concepts of authoritarianism and violence in The White King book, which are decisive, not only for the development of the plot, but also for the transformation of the narrator-character: Dzsátá.
\end{abstract}

Keywords: Authoritarianism; Violence; György Dragomán; The White King.

\section{CONSIDERAÇÕES INICIAIS}

A obra $O$ rei branco, de György Dragomán - publicada originalmente em húngaro em 2005, e traduzida no Brasil em 2009 - trata da história de um menino de 11 anos, cujo pai havia sido levado pela polícia do Estado, para um campo de trabalhos forçados para a construção do canal do Danúbio. A história transcorre durante o período de um ano e meio, no qual o narrador personagem descreve diversas experiências de sua infância, marcada pela ausência do pai e pela opressão de um regime autoritário que, para se manter no poder, utiliza-se de diversos meios de "convencimento", desde as propagandas ideológicas até as ameaças e atos de violência.

\footnotetext{
${ }^{1}$ Técnico Do Ensino Superior na UNEMAT. Mestre em Estudos Literários pelo Programa de Pós-Graduação em Letras da Universidade Federal de Santa Maria (UFSM). E-mail: jildoneilazzaretti@ hotmail.com

${ }^{2}$ Doutora em Educação pela Universidade Federal de Santa Maria (UFSM). Doutoranda em Estudos Literários do Programa de Pós-Graduação em Letras da Universidade Federal de Santa Maria (UFSM). E-mail: teacheradrianacm@hotmail.com
} 
No presente artigo analisaremos as manifestações de autoritarismo e de violência presentes na narrativa de Dragomán. Em tal análise, serão considerados os dois conceitos a partir do Dicionário de Política, de Bobbio el al. (1998), bem como a partir da reflexão teórica e alegórica de Wolfgang Sofsky no Tratado sobre la violencia (2006). Antes disso, analisaremos as principais referências espaço-temporais mencionadas no texto, as quais fornecem ainda mais elementos para que compreendamos as especificidades do regime autoritário e violento presente na narrativa ficcional de O rei branco.

\section{AS REFERÊNCIAS ESPAÇO-TEMPORAIS NA OBRA}

Alguns leitores e até alguns críticos olham para $O$ rei branco como se fosse uma narrativa distópica, que supostamente estaria fazendo referência a governos autoritários de forma genérica, sem se identificar com determinado período histórico ou localização geográfica. A própria adaptação cinematográfica da obra ${ }^{3}$, cria uma "pátria imaginária" - com símbolos e heróis próprios - na qual se desenvolvem as ações da narrativa. No entanto, mesmo tratando-se de uma obra ficcional, podemos afirmar, a partir de informações presentes no texto, que o contexto espaço-temporal refere-se a um regime de governo, historicamente, existente.

No que se refere à localização geográfica, mesmo não havendo referências explícitas, podemos afirmar, a partir de dados textuais, que a história desenvolve-se na Romênia. A primeira informação que justifica isso é dada pelo protagonista Dzsátá ao afirmar: "eu comecei a pensar que papai talvez tivesse fugido do país, como o pai de um colega meu de classe, Egon, que atravessou o Danúbio a nado e foi para a Iugoslávia e de lá para o Ocidente" (DRAGOMÁN, 2009, p. 10). Geograficamente, a Romênia é o único país que fazia fronteira com a, então, Iugoslávia (atual Sérvia), e possui essas mesmas fronteiras delimitadas pelo rio Danúbio.

Outro dado é a evocação, feita por um dos irmãos Lupu, do nome de "Tudor Vladimirescu, para que lhe desse sorte" (DRAGOMÁN, 2009, p. 207). Tudor Vladimirescu é considerado, na Romênia, um herói nacional, por ter sido líder da insurreição de 1821. Inclusive, seu nome foi dado a uma divisão de voluntários romenos, criada em 02 de outubro de 1943, na URSS, com a missão de colocar o Partido Comunista no poder, pela força de armas, na Romênia, e usando como pretexto o combate aos nazistas no final da Segunda Guerra Mundial.

Na narrativa, há também uma referência histórica muito recorrente, que remete, não apenas à Romênia, mas também ao governo comunista que lá existiu até o ano de 1989. Trata-se das constantes

\footnotetext{
${ }^{3}$ Filme The White King (2016), dirigido por Alex Helfrecht e Jörg Tittel.
} 
menções à construção do canal do Danúbio, cuja primeira ocorrência constatamos no momento em que os oficiais da polícia do Estado invadem a casa da mãe de Dzsátá, e revelam para onde seu pai tinha sido levado:

[...] o de cabelo grisalho sorriu para mim e disse que era bom eu saber que eles não eram colegas do meu pai, mas pertenciam ao serviço secreto, que meu pai estava preso porque tinha participado de atividades contra o governo, de modo que por algum tempo eu certamente não o veria, ou melhor, por muito tempo, porque meu pai trabalhava nas obras do canal do Danúbio, se eu sabia o que isso significava, significava que ele estava em um campo de trabalhos forçados, e como era frágil, não suportaria durante muito tempo e não voltaria nunca mais, talvez nem estivesse vivo (DRAGOMÁN, 2009, p. 14 -15).

De acordo com a historiadora e jornalista Anne Applebaum, em sua obra Gulag: uma história dos campos de prisioneiros soviéticos (2004), os campos de trabalhos forçados "se espalhavam por todo o comprimento e toda a largura da URSS, das ilhas do mar Branco às costas do mar Negro, do Círculo Ártico às planícies da Ásia central, de Murmansk a Vorkuta e ao Cazaquistão, do centro de Moscou à periferia de Leningrado" (APPLEBAUM, 2004, p. 13). Esses campos de trabalhos forçados eram chamados de Gulag, que é a sigla de "Glavnoe Upravlenie Lagerei”, ou Administração Central dos Campos. Segundo Applebaum (2004), o regime soviético também influenciou os regimes comunistas dos países vizinhos no que se refere à implantação de campos de trabalhos forçados: “Também existiam campos na Romênia, na Bulgária e - apesar da reputação de anti-soviético - na Iugoslávia de Tito. [...] A maioria fora criada pela polícia local com orientação dos soviéticos." (APPLEBAUM, 2004, p. 514). A historiadora destaca que os campos romenos eram os que mais se assemelhavam com os soviéticos, sendo o do canal do Danúbio o mais importante deles, principalmente por constituir-se em um eficaz instrumento para torturar até a morte os opositores do regime comunista romeno:

A polícia secreta romena, a Securitate, parece ter trabalhado sob as ordens diretas das congêneres soviéticas. Por essa razão, talvez, os campos romenos sejam os que mais lembravam o Gulag, ao ponto de levarem a cabo projetos ambiciosos e absurdos como os que o próprio Stalin privilegiava na União Soviética. O mais famoso, o Canal Mar Negro-Danúbio, aparentemente não teve função econômica. Até hoje ele está totalmente vazio e abandonado [...]. Um slogan de propaganda declarava que o "Canal Mar Negro-Danúbio é o túmulo da burguesia romena!" Como cerca de $200 \mathrm{mil}$ pessoas devem ter morrido em sua construção, esse pode ter sido de fato seu real objetivo (APPLEBAUM, 2004, p. 514).

Também o historiador Tony Judt, em sua obra Pós-guerra: uma história da Europa desde 1945, afirma que "talvez a pior perseguição tenha ocorrido na Romênia — certamente, foi a mais duradoura" (JUDT, 2011, p. 191). Segundo ele, havia "mais de um milhão de detidos, em penitenciárias, campos 
de trabalho forçado e trabalho escravo na construção do canal de ligação entre o Danúbio e o mar Negro, dos quais dezenas de milhares sucumbiram e cujas estatísticas não incluem os deportados para a União Soviética" (JUDT, 2011, p. 191).

Além da referência aos trabalhos forçados para construção do canal do Danúbio, em $O$ rei branco também constam menções aos “campos de reeducação" (DRAGOMÁN, 2009, p. 148). Acerca desse tema, Tony Judt (2011, p. 191) afirma que "a Romênia se destacou pela severidade das condições nas várias "penitenciárias experimentais", em que "os prisioneiros foram incentivados a se 'reeducarem' mutuamente, recorrendo à tortura física e psicológica. A maioria das vítimas era de estudantes, "sionistas" e presos políticos não comunistas" (JUDT, 2011, p. 191).

No que se refere à identificação do regime autoritário presente em $O$ rei branco com um governo comunista, pode ser justificada pela constante utilização, ao longo da obra, da expressão "camarada" - própria da ideologia comunista - sendo usada, na narrativa, como um pronome de tratamento para se dirigir a toda espécie de autoridade, desde os professores até os governantes. Essa vinculação ao comunismo também é constatada no episódio da distribuição de alimentos, quando é mencionado que as bananas que estavam sendo distribuídas no armazém estavam em caixas de madeira, nas quais estava "impresso CUBA em grandes letras pretas" (DRAGOMÁN, 2009, p. 189).

Outra referência temporal muito relevante na obra é a passagem em que um coronel do exército tenta convencer Dzsátá e seu amigo Janika a perderem a partida de futebol contra o time dos filhos dos oficiais, e utiliza o seguinte pretexto: "o coronel disse que de noite havia acontecido um acidente em uma usina nuclear na União Soviética e o vento havia trazido a radioatividade para cá" (DRAGOMÁN, 2009, p. 33). Tal acidente pode ser imediatamente associado com a explosão de uma usina nuclear de Chernobyl (atual território da Ucrânia), que ocorreu em 26 de abril de 1986.

Portanto, os referidos dados textuais indicam que a história ficcional de $O$ rei branco possui como contexto espaço-temporal a Romênia entre os anos de 1986 e 1989, durante o regime comunista no país. Deste modo, acreditamos que seja inconcebível uma interpretação distópica de tal obra, a não ser que o texto em si seja ignorado, e que se busque esse tipo de interpretação por conveniência ideológica. 


\section{O AUTORITARISMO EM DIVERSAS INSTÂNCIAS}

Embora o significado do termo "autoritarismo" possa parecer tão evidente, por ser largamente utilizado e aplicado a diversas circunstâncias do cotidiano, vemos que é necessário buscar uma precisão conceitual, a fim de que possamos relacionar adequadamente os fenômenos vinculados a tal conceito com a obra de György Dragomán. Nesse sentido, recorremos ao Dicionário de política, de Norberto Bobbio et al. (1998), cujo verbete "autoritarismo" foi escrito por Mario Stoppino. Ao definir o conceito, o autor destaca que ele pode ser aplicado "especificamente em três contextos: a estrutura dos sistemas políticos, as disposições psicológicas a respeito do poder e as ideologias políticas" (BOBBIO et al, 1998, p. 94). Essas três dimensões estão presentes de algum modo na obra $O$ rei branco, como buscaremos demonstrar.

Em relação à estrutura dos sistemas políticos, o Dicionário de política destaca que autoritários são "os regimes que privilegiam a autoridade governamental e diminuem de forma mais ou menos radical o consenso, concentrando o poder político nas mãos de uma só pessoa ou de um só órgão e colocando em posição secundária as instituições representativas.” (BOBBIO et al, 1998, p. 94). Na obra $O$ rei branco, tal realidade de predomínio da autoridade governamental, por meio da centralização do poder político, pode ser constatada na figura do partido comunista, cuja autoridade é exercida em diversos âmbitos: desde algo simples como nome do time de futebol infantil que se chamava "Martelo Vermelho" (DRAGOMÁN, 2009, p. 29), até algo mais violento como os oficiais levando o pai de Dzsátá para um campo de trabalhos forçados no canal do Danúbio (Cf. DRAGOMÁN, 2009, p. 8) e, depois, invadindo e revistando sua casa sem mandado (Cf. DRAGOMÁN, 2009, p. 15). Além disso, observa-se a imposição da censura pelo partido de modo que "existiam coisas de que até mesmo falar era perigoso" (DRAGOMÁN, 2009, p. 149); bem como o incentivo das autoridades aos supostos "pensamentos patrióticos" que "faziam o Estado progredir no caminho da paz" (DRAGOMÁN, 2009, p. 86).

Nesse contexto do autoritarismo político, "a oposição e a autonomia dos subsistemas políticos são reduzidas à expressão mínima e as instituições destinadas a representar a autoridade de baixo para cima ou são aniquiladas ou substancialmente esvaziadas.” (BOBBIO et al, 1998, p. 94). Essa redução e perseguição aos opositores são uma constate em $O$ rei branco, tendo como um dos exemplos o avô de Dzsátá, o Camarada Secretário, que teve de renunciar ao seu cargo quando se soube que seu filho havia assinado uma petição contra o regime, como descreve o menino: 
Meu avô nunca havia mencionado meu pai [...] de tanto que se ressentia pelo fato de meu pai ter sujado nosso nome, havia envergonhado a si mesmo e à família quando assinara a petição [...] havia sido um escândalo tremendo, meu avô tivera de renunciar e de se aposentar imediatamente, e devia se dar por satisfeito por não the ter acontecido nada de mais grave (DRAGOMÁN, 2009, p. 231).

Além disso, outros acontecimentos na narrativa indicam a existência de um Estado autoritário bem estruturado, cujas ramificações e poderio estendem-se sobre os mais diversos âmbitos da

sociedade, como pode ser constatado na própria existência dos campos de trabalhos forçados e dos campos de reeducação (Cf. DRAGOMÁN, 2009, p. 148), bem como o medo das pessoas de serem seguidas pela segurança estatal (Cf. DRAGOMÁN, 2009, p. 228), e até mesmo as retaliações aos familiares dos que se opuseram ao Estado, como relata Dzsátá: "quando se revelou oficialmente que meu pai havia sido levado, ele me excluiu do time dos Defensores da Pátria” (DRAGOMÁN, 2009, p. 76).

Em relação ao sentido psicológico do termo "autoritarismo", o Dicionário de política destaca que a pessoa autoritária é aquela que se dispõe à obediência aos superiores e ao desprezo dos inferiores:

Em sentido psicológico, fala-se de personalidade autoritária quando se quer denotar um tipo de personalidade formada por diversos traços característicos centrados no acoplamento de duas atitudes estreitamente ligadas entre si: de uma parte, a disposição à obediência preocupada com os superiores, incluindo por vezes o obséquio e a adulação para com todos aqueles que detêm a força e o poder; de outra parte, a disposição em tratar com arrogância e desprezo os inferiores hierárquicos e em geral todos aqueles que não têm poder e autoridade. (BOBBIO et al, 1998, p. 94).

Nesse sentido, podemos identificar diversas personalidades autoritárias em $O$ rei branco. A mais emblemática delas, certamente, é o embaixador a quem a mãe de Dzsátá recorre para obter notícias sobre o marido levado para o canal do Danúbio, mas que apenas se aproveita dela sexualmente, e depois a humilha, expulsando-a de sua casa junto com o filho:

[...] ele começou a gritar até que enfim você está aqui, tinha chegado a hora de eu cair fora, e era também hora de levar comigo a puta da minha mãe, ele não sabia por que nos havia deixado entrar na sua casa, pois deveria saber como nós éramos, meu avô também não valia merda nenhuma, seria bom se esquecêssemos meu pai para sempre, porque nunca na vida o veríamos de novo, ele nos garantia que ele iria morrer lá onde estava, apodreceria no canal do Danúbio, eu deveria ficar feliz se ele não fosse enviado a um campo de reeducação, nós não o veríamos nunca mais (DRAGOMÁN, 2009, p. 148). 
Outra personalidade autoritária era a do diretor da escola de Dzsátá, que exigia a obediência das crianças ameaçando-as e insultando-as:

[...] o camarada diretor se esguelava, estava de pé diante da plateia, ouvimos bem de pé perto que ele gritava para que todos ficassem no lugar, [...] e quem não estivesse no lugar quando a luz voltasse ele enfiaria num poste, e mandaria pendurar no pátio da escola e arrancaria seu coração pessoalmente, porque havia chegado o tempo de esse bando de ordinários, inúteis, desprezíveis aprender de uma vez por todas o que era disciplina [...] (DRAGOMÁN, 2009, p. 194)

Nesse contexto autoritário, até mesmo as próprias crianças, em suas relações interpessoais, desenvolviam uma personalidade autoritária, como Rômulo Fronza ao afirmar para Dzsátá "que ali era ele quem dizia o que era justo e o que não era” (DRAGOMÁN, 2009, p. 122). Ou também o garoto Prodán ao ser colocado como "chefe da brigada", fiscalizando as crianças na escavação: "Prodán, naturalmente, já tinha parado de trabalhar havia muito, e com a pá na mão andava às nossas costas e nos mandava continuar trabalhando" (DRAGOMÁN, 2009, p. 44).

Já no que se refere ao autoritarismo enquanto ideologia, o Dicionário de política define que são aquelas que basicamente se pautam na desigualdade entre os homens para sustentar seus regimes:

As ideologias autoritárias, enfim, são ideologias que negam de uma maneira mais ou menos decisiva a igualdade dos homens e colocam em destaque o princípio hierárquico, além de propugnarem formas de regimes autoritários e exaltarem amiudadas vezes como virtudes alguns dos componentes da personalidade autoritária. (BOBBIO et al, 1998, p. 94).

Essa defesa ideológica da desigualdade, a fim de sustentar uma hierarquia autoritária, pode ser constatada na relação entre professores e alunos, a qual era mediada pelos alunos monitores:

[...] tio Kildész entrou, o professor de matemática, a classe se pôs de pé e o tio Kildész se dirigiu para o estrado e atirou com força a lista de presença sobre a mesa, como de costume, e em seguida olhou para nós e esperou a comunicação, [...] Iza se adiantou e cumprimentou, e, como se deve, disse comunico para o camarada professor que o número de alunos e assim por diante, [...] e então Iza relacionou os faltosos e encerrou a comunicação e tio Kildész concordou e disse que poderíamos nos sentar (DRAGOMÁN, 2009, p. 64-65).

Tal ideologia também está presente na ocasião em que as crianças são forçadas a trabalhar na escavação: "são vocês que vão escavar uma parte da vala, assim, com um trabalho coletivo, para economizar óleo diesel para o país" (DRAGOMÁN, 2009, p. 42). Como podemos observar, essa ideologia autoritária, baseada na desigualdade, é sustentada pela exaltação do trabalho coletivo - de alguns, obviamente - para construção de uma suposta pátria de todos: "vão ver como é bonito um trabalho coletivo voluntário como esse, como faz bem construir o país, vocês devem sentir orgulho 
por tomarem parte disso como crianças, se trabalharem bem, terminam tudo em uma semana" (DRAGOMÁN, 2009, p. 43).

Também a existência de uma sala secreta de cinema, descoberta por Dzsátá e Feri, indica essa ideia de desigualdade. A própria estrutura dessa sala de cinema, com a disposição de suas poltronas, indica que aqueles que ali se sentavam pertenciam a uma organização hierárquica: "Estávamos em uma sala normal de cinema, porém sem cadeiras, mas com poltronas de couro muito grandes, no meio do salão havia duas juntas, atrás delas, de cada lado, em semicírculo, mais umas dez" (DRAGOMÁN,

2009, p. 200). No momento em que estavam na sala secreta, Dzsátá manifestou seu temor de ser descoberto e considerado um traidor da pátria, demonstrando que tal mentalidade autoritária permeava toda a sociedade, sendo evidente até mesmo para uma criança: "seria melhor se voltássemos, pois se alguém nos pegasse seria o fim, porque todos esses lugares proibidos contavam como instalações militares, e entrar numa delas era com certeza traição à pátria” (DRAGOMÁN, 2009, p. 201).

Uma característica comum dos três níveis de autoritarismo - político, psicológico e ideológico - é "a centralidade do princípio de autoridade" (BOBBIO et al, 1998, p. 94), que é garantida por "um notável emprego de meios coercitivos” (BOBBIO et al, 1998, p. 94). Tais meios de coerção, normalmente, possuem como principal forma a violência física.

\section{A VIOLÊNCIA COMO INSTRUMENTO DO AUTORITARISMO NA NARRATIVA DE UMA CRIANÇA}

Do Dicionário de política servimo-nos também para explicar o conceito de violência, que consiste na "intervenção física de um indivíduo ou grupo contra outro indivíduo ou grupo" (BOBBIO et al, 1998, p. 1291). A violência, consequentemente, tem por alvo a destruição, a injúria e a repressão. $\mathrm{O}$ autor ainda assinala que a violência pode ser direta ou indireta. Assim, Bobbio esclarece que a violência é "direta quando atinge de maneira imediata o corpo de quem a sofre. É indireta quando opera através de uma alteração do ambiente físico no qual a vítima se encontra” (BOBBIO et al, 1998, p. 1291).

Deste modo, ao aproximarmos esta definição de violência com a narrativa de Dragomán (2009), parece-nos possível atribuir ao termo violência um sentido descritivo, o qual poderia ser um sinônimo de força (BOBBIO et al, 1998). Se considerarmos o personagem Dzsátá, ainda que ele esteja brincando e fazendo coisas de um menino de 11 anos de idade, paralelamente à sua rotina, identificamos que o personagem observa o mundo configurado pelo regime repressor e explicita sua incompreensão das 
coisas que vê nesse contexto. Na perspectiva de tecer uma apreciação sobre a narrativa de Dragomán, o fragmento que segue exemplifica um evento da infância vivida dentro de um regime repressivo:

Enquanto isso, os soldados continuavam lá, o tempo todo, o oficial só ficava olhando e os demais andavam em volta do campo metidos naquelas roupas estranhas, empurravam máquinas cheias de canos e fios, nas mãos também tinham toda espécie de ferramentas esquisitas, cheias de fios e antenas, eu não sabia o que estavam fazendo, pensei que talvez quisessem transmitir o jogo pelo rádio, mas nunca tinha ouvido falar de nada parecido antes, as máquinas zumbiam e rangiam muito, embora eu não conseguisse prestar muita atenção nelas pois tinha de correr e de pular e de me atirar no chão. (DRAGOMÁN, 2009, p. 31).

Adentramos ao pensamento do menino e de sua suposição de que não haveria algo mais além da possibilidade de um jogo ser transmitido pelo rádio quando da presença de antenas e fios às margens do campo. A partir da perspectiva da criança, é possível estabelecer relações entre violência e poder. Vale sublinhar que Dzsátá é um menino que tem como rotina esperar por seu pai. É o próprio narradorpersonagem quem nos conta sobre essa sua esperança.

[...] aos domingos sempre ficava em casa, costumava esperar pelo meu pai, porque quando o levaram para o canal do Danúbio ele tinha prometido que voltaria e me levaria com ele, é verdade que minha mãe tinha dito que eu não o esperasse porque era possível que depois de oito meses de trabalhos forçados talvez eu não o reconhecesse [...] eu achava que talvez meu pai não estivesse em um campo de trabalhos forçados, mas apenas em uma instituição secreta de pesquisa, como ele tinha dito, porque eu havia lido que quando os americanos fizeram a bomba atômica em Los Alamos ninguém podia saber onde os cientistas estavam de verdade, e sabia que meu pai voltaria para casa sim, viria me buscar e me levaria com ele, me levaria para o mar, e eu sabia que ainda que ele não me reconhecesse eu o reconheceria, porque a fotografia do tempo de militar que tinha achado entre os livros velhos sempre estava comigo, de modo que eu queria ir para casa, mal podia esperar que tomássemos mais um gol e que o jogo terminasse. (DRAGOMÁN, 2009, p. 37-38).

A partir desse fragmento da memória de Dzsátá, durante uma partida de futebol, identificamos em sua narrativa como o medo guia suas ações e como a tomada de consciência acerca do regime autoritário vai acontecendo ao longo da história de sua vida. O personagem narra a visão prospectiva do que aconteceria, sempre na dimensão de que ele poderá ser corrigido, violentamente, caso não possa se adequar às normas e às vontades dos mais fortes, pois, ainda que dentre as relações com os colegas da escola, o medo está presente nos sentimentos de Dzsátá.

Sabíamos que se não adoecêssemos no dia seguinte seria o nosso fim, os demais nos dariam uma surra na escola porque descobririam que o dinheiro da classe, com que tínhamos de comprar o tecido da bandeira e o material para o cartaz do Primeiro de Maio, havíamos torrado sem querer na máquina do porão do teatro de marionetes, no 
salão de jogos, porque Feri tinha mentido que nas máquinas novas cada terceiro jogador ganhava automaticamente [...] (DRAGOMÁN, 2009, p. 19-20).

A violência e o medo estão implícitos também nas marcas e sentidos da angústia de Dzsátá, que estão presentes na narrativa e garantem que reconheçamos o sofrimento dele diante dos acontecimentos de sua vida. A situação que o protagonista descreve no vestiário, elucida esse sofrimento:

[...] ele acertou o rosto de Janika, e então eu ouvi algo rachando, Janika bateu no cabide [...] vi que Janika estava estendido no chão junto do cabideiro do vestiário, e também vi que ele não se mexia e seu ouvido sangrava, senti que a bola estava um pouco grudenta, sabia que era do sangue de Janika, enquanto a segurava pensei na radioatividade, mas não senti nada, ao toque a bola parecia estar exatamente como das outras vezes, por um instante eu fechei os olhos e fiquei ali sem me mexer com a bola entre as mãos, e quando os abri tio Gica continuava parado na porta e Janika continuava deitado no chão imóvel [...] e então de repente minhas lágrimas começaram a correr, a bola caiu de minhas mãos, quicou, depois correu para um canto, mas nessa hora tio Gica não estava mais no vestiário. (DRAGOMÁN, 2009, p. 3536).

Essa experiência de Dzsátá, testemunhando um ato de violência contra seu amigo, pode ser relacionada com as considerações de Sofsky no Tratado sobre la violência (2006), em que o autor afirma: “A origem da sociedade não está no que o homem faz, mas no que ele sofre" ${ }^{4 ”}$ (SOFSKY, 2006, p. 09, tradução nossa). Essa afirmação permite-nos trazer à discussão a questão que envolve o entendimento de liberdade e as limitações que são impostas pela vida em sociedade. $\mathrm{O}$ que a pessoa sofre é constitutivo da e na sociedade, e sua liberdade está atrelada a formatar-se dentro de um contrato social, administrado por certo medo.

Assim, Sofsky esclarece que este medo é o que ratifica tal contrato, o qual é pré-determinado por aqueles que detêm o poder e, consequentemente, possuem autoridade sobre os demais. E, contra o poder e a autoridade não há combate possível, pois está naturalizada a opressão dentro da ordem política. Sofsky (2006, p. 11) esclarece que o medo "reaparece, cresce, muda de motivo e forma. A violência de modo algum desaparece, apenas muda de face ${ }^{5}$. Na narrativa, Dragomán dá voz ao protagonista que expressa, na sua inocência e sofrimento, a crueldade naturalizada pelo regime repressivo comunista.

Dzsátá, devido à violência que o cerca, fica receoso até mesmo de vivenciar atos próprios da vida de uma criança, como comer um caramelo. Portanto, a violência o priva de sua própria infância,

\footnotetext{
4 "El origen da sociedad no está en lo que el hombre hace, sino en lo que padece".

5 "reaparece, asciende, cambia de motivo y forma. La violencia en modo alguno desaparece, sólo cambia de rostro".
} 
pois exibe a tentativa do autor de representar e se manter no mundo de uma criança, no doce do caramelo. No entanto, sua realidade restringe-se a um caramelo sem sabor e com o papel. Esse episódio do caramelo demonstra que a vida impôs ao menino Dzsátá um comportamento de obediência e de silêncio mediante a ordem imposta:

[...] o trabalhador então olhou para mim, o que há perguntou, você não quer?, depois deu um passo na minha direção [...] você pode comer sim, em seguida enfiou a mão no saco e tirou um caramelo, estendeu-o para mim entre dois dedos e mandou que eu abrisse a boca, a mão dele era muito grande [...] meu estômago se revirou, eu quis cuspir, mas eles apertaram minha boca e de novo prenderam meu nariz, nem senti o gosto do caramelo, apenas senti que ele derretia com papel e tudo entre os meus dentes, depois eles me soltaram, caí no chão e tentei cuspir, mas não havia mais nada na minha boca [...] (DRAGOMÁN, 2009, p. 40-41).

Nesta perspectiva, o estudo de Sofsky (2006) afirma que a violência é um dos meios e condições para imposição da ordem em uma sociedade. No Tratado sobre la violência, Sofsky identifica o paradoxo de que os seres humanos são violentos, mas vivem em uma sociedade que proíbe a violência. No capítulo “Ordem e violência”, Sofsky (2006, p. 05) afirma:

Quando todos os homens eram livres e iguais, ninguém se sentia seguro diante dos outros. A vida era curta e o medo imenso. Nenhuma lei protegia ninguém da agressão. Todos desconfiavam de todos, e todos tinham que se proteger, pois até o mais fraco era forte o suficiente para machucar ou matar o mais forte, a traição ou em conspiração com um terceiro. Então, os homens estabeleceram uma aliança para a segurança de $\operatorname{todos}^{6}$ (SOFSKY, 2006, p. 05, tradução nossa).

Assim, podemos entender que a decisão de proibir a violência mediante leis dá-se diante de uma sociedade que é essencialmente violenta, na qual algumas pessoas poderiam portar armas em defesa das demais. Foi assim que aqueles que deveriam manter a segurança foram escolhidos. Outros foram eleitos para promulgar leis de controle social. Por conseguinte, foram criadas instituições para reter quem não cumprisse a lei e para educar as gerações futuras, garantindo, deste modo, o controle e a ordem. É nesse meio que Dzsátá cala e, ao mesmo tempo, conta-nos os momentos de sua trajetória de menino, enquanto guia-se pela saudade de seu pai e pela esperança de revê-lo.

$\mathrm{Na}$ narrativa, tal reflexão acerca do comportamento das pessoas e do uso de armas está assinalada na passagem em que Dzsátá é perseguido e agredido pelos irmãos Lupu, sendo salvo pela

\footnotetext{
6 "Cuando todos los hombres eran libres e iguales, nadie se sentía seguro ante los demás. La vida era breve, y el miedo inmenso. Ninguna ley protegía a nadie de la agresión. Todo el mundo desconfiaba de todo el mundo, y de todo el mundo tenía que protegerse. Pues aun el más débil era lo bastante fuerte como para herir o matar al más fuerte, a traición o en confabulación con un tercero. Entonces los hombres establecieron una alianza para su común seguridad”.
} 
ajuda de Picareta. O protagonista nos conta que "[...] todos voavam como podiam, Picareta jogou no chão a marreta junto do cano de ferro, olhou para mim, disse que não sabia onde íamos parar, no seu tempo os garotos ainda sabiam o que era uma briga honesta, um contra um, de mãos vazias [...]" (DRAGOMÁN, 2009, p. 211).

Também está presente, ao longo da narrativa, a violência institucionalizada, como instrumento de um regime autoritário. Certamente o embaixador é a principal figura representativa de tal violência, pois, além de ter abusado da mãe de Dzsátá e a humilhado, antes disso também ameaçou furar os olhos do menino, se ele roubasse algum objeto de sua casa:

[...] chegamos diante de uma porta que o embaixador abriu, ele me conduziu para ela, mas não entrou, apenas parou na porta e disse que eu deveria ser um bom rapaz e deveria esperar pela minha mãe e não deveria tocar em nada, e, principalmente, não deveria tentar roubar nada, pois pagaria por isso, em seguida disse de novo que conhecia bem as crianças, sabia que eram todas pequenas ladras em que não se podia confiar um instante sequer, de modo que era para eu me cuidar, pois no lugar de onde aqueles objetos vinham se costumava furar os olhos dos ladrões (DRAGOMÁN, 2009, p. 143, grifos nossos).

Essa violência institucional também é assimilada pela sociedade em suas relações interpessoais, sendo incorporada, inclusive, pelas crianças. É nesse sentido que Dzsátá no início da narrativa parece tão ingênuo - descrevendo detalhadamente como colheu as tulipas no lugar do pai, que, na sua visão, tinha viajado para um centro de pesquisas - mas depois assimila também a violência que o cerca. Isso pode ser constatado no momento em que Dzsátá fica tomado de ciúmes por sua mãe ter repartido seu "túnel de castanhas" com Máriusz, um menino de seis anos que vendia cabides e prendedores. A raiva de Dzsátá é tamanha que ele pensa até em atirar uma faca na cabeça de Máriusz:

[...] eu fui depressa para o meu quarto, subi na cama e abri a janela e vi Máriusz saindo do bloco de apartamentos para a calçada, e então empunhei a faca, respirei fundo, mas depois acabei não tentando atingi-lo na cabeça, sabia que não acertaria, porque infelizmente ele estava muito longe (DRAGOMÁN, 2009, p. 183).

\section{CONSIDERAÇÕES FINAIS}

A partir do que foi exposto, constatamos que, na obra $O$ rei branco, a presença de acontecimentos marcados pelo autoritarismo e pela violência, não são apenas questões secundárias, mas são determinantes para o desenvolvimento do enredo e, principalmente, para o processo de constituição e transformação do narrador-personagem Dzsátá. Essa transformação - mediada pelas 
circunstâncias autoritárias e violentas - pode ser percebida a partir de um paralelo entre o primeiro e o último capítulo da obra. No primeiro capítulo, Dzsátá é um menino que crê no retorno do pai, e sonha com a promessa que ele lhe fizera de que o levaria para conhecer o mar. Já no último capítulo, um ano e meio depois, Dzsátá é alguém que, tendo vivenciado as situações de opressão e de violência, sabe que a única forma de trazer seu pai de volta é enfrentando o sistema político autoritário que os governa, e realiza esse enfrentamento também por meio da violência. Nesse sentido, é emblemática a imagem final da narrativa, quando Dzsátá erguendo uma barra de ferro, corre atrás do camburão que leva seu pai como prisioneiro. Ele luta contra o autoritarismo, usando-se justamente do principal instrumento dos autoritários, a violência.

\section{REFERÊNCIAS}

APPLEBAUM, A. Gulag: uma história dos campos de prisioneiros soviéticos. Trad. Mário Vilela e Ibraíma Dafonte. Rio de Janeiro: Ediouro, 2004.

BOBBIO et al. Dicionário de Política. Trad. João Ferreira et al. 11. ed. Brasília: UnB, 1998.

DRAGOMÁN, G. O rei branco. Trad. Paulo Schiller. Rio de Janeiro: Intrínseca, 2009.

JUDT, T. Pós-guerra: uma história da Europa desde 1945. Trad. José Roberto O’Shea; rev. Marta Miranda O'Shea. Rio de Janeiro: Objetiva, 2011.

SOFSKY, W. Tratado sobre la violencia. Trad. Joaquín Chamorro Mielke. Madrid: Abada Editores, 2006.

Recebido em 15/0/2018

Aceito em 28/12/2018 